\title{
Methods for the synthesis of polyhydroxylated piperidines by diastereoselective dihydroxylation: Exploitation in the two-directional synthesis of aza-C- linked disaccharide derivatives
}

\author{
Andrew Kennedy ${ }^{1}$, Adam Nelson ${ }^{*} 2$ and Alexis Perry ${ }^{3}$
}

\section{Full Research Paper}

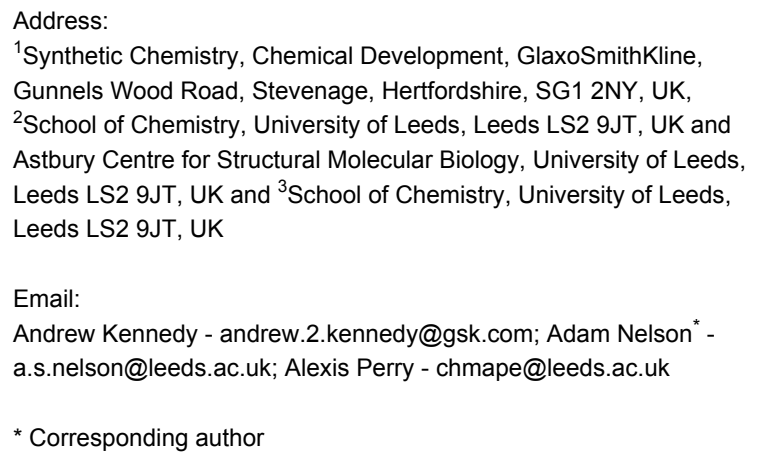

${ }^{1}$ Synthetic Chemistry, Chemical Development, GlaxoSmithKline, Gunnels Wood Road, Stevenage, Hertfordshire, SG1 2NY, UK, ${ }^{2}$ School of Chemistry, University of Leeds, Leeds LS2 9JT, UK and Astbury Centre for Structural Molecular Biology, University of Leeds, Leeds LS2 9JT, UK and ${ }^{3}$ School of Chemistry, University of Leeds, Leeds LS2 9JT, UK

\section{Email:}

Andrew Kennedy - andrew.2.kennedy@gsk.com; Adam Nelson* a.s.nelson@leeds.ac.uk; Alexis Perry - chmape@leeds.ac.uk

* Corresponding author

Beilstein Journal of Organic Chemistry 2005, 1, No. 2. doi:10.1186/1860-5397-1-2

Received: 17 June 2005

Accepted: 26 August 2005

Published: 26 August 2005

(c) 2005 Kennedy et al; licensee Beilstein-Institut.

License and terms: see end of document.

\begin{abstract}
Background:

Many polyhydroxylated piperidines are inhibitors of the oligosaccharide processing enzymes, glycosidases and glycosyltransferases. Aza- $C$-linked disaccharide mimetics are compounds in which saturated polyhydroxylated nitrogen and oxygen heterocycles are linked by an all-carbon tether. The saturated oxygen heterocycle has the potential to mimic the departing sugar in a glycosidase-catalysed reaction and aza- $C$-linked disaccharide mimetics may, therefore, be more potent inhibitors of these enzymes.
\end{abstract}

\section{Results:}

The scope, limitations and diastereoselectivity of the dihydroxylation of stereoisomeric 2-butyl-1-(toluene-4-sulfonyl)-1,2,3,6tetrahydro-pyridin-3-ols is discussed. In the absence of a 6-substituent on the piperidine ring, the Upjohn (cat. $\mathrm{OsO}_{4}, \mathrm{NMO}$, acetone-water) and Donohoe $\left(\mathrm{OsO}_{4}\right.$, TMEDA, $\left.\mathrm{CH}_{2} \mathrm{Cl}_{2}\right)$ conditions allow complementary diastereoselective functionalisation of the alkene of the $\left(2 R^{*}, 3 R^{*}\right)$ diastereoisomer. However, in the presence of a 6 -substituent, the reaction is largely controlled by steric effects with both reagents. The most synthetically useful protocols were exploited in the two-directional synthesis of aza- $C$-linked disaccharide analogues. A two-directional oxidative ring expansion was used to prepare bis-enones such as $(2 R, 6 S, 2$, $S$ )-6-methoxy2-(6-methoxy-3-oxo-3,6-dihydro-2H-pyran-2-ylmethyl)-1-(toluene-4-sulfonyl)-1,6-dihydro-2H-pyridin-3-one from the corresponding difuran. Selective substitution of its $N, O$ acetal was possible. The stereochemical outcome of a two-directional Luche reduction step was different in the two heterocyclic rings, and depended on the conformation of the ring. Finally, two-directional diastereoselective dihydroxylation yielded seven different aza- $C$-linked disaccharide analogues. 


\section{Conclusion:}

A two-directional approach may be exploited in the synthesis of aza- $C$-linked disaccharide mimetics. Unlike previous approaches to similar molecules, neither of the heterocyclic rings is directly derived from a sugar, allowing mimetics with unusual configurations to be prepared. The work demonstrates that highly unsymmetrical molecules may be prepared using a two directional approach. The deprotected compounds may have potential as inhibitors of oligosaccharide-processing enzymes and as tools in chemical genetic investigations.

\section{Introduction}

Many polyhydroxylated piperidines are potent inhibitors of the oligosaccharide processing enzymes, glycosidases and glycosyltransferases.[1-3] For example, deoxymannojirimycin, 1, and deoxynojirimycin, 2, are selective mannosidase and glucosidase inhibitors respectively.[4,5] In these molecules, the nitrogen atom is protonated at physiological $\mathrm{pH}$ and the transition state for glycosidase-catalysed reaction is mimicked effectively.[6] Glycosidase inhibitors have potential in the treatment of viral infections, [7-10] cancer[11,12] and diabetes and other metabolic disorders.[13-15]<smiles>OC[C@H]1NC[C@@H](O)[C@H](O)[C@H]1O</smiles>

1

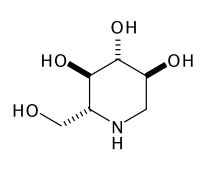

2

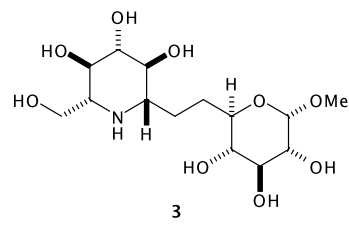

Aza-C-linked disaccharides, such as $\mathbf{3}$, possess a second sugar unit which may resemble the departing sugar and thereby impart greater selectivity and potency for the targeted enzyme. The $\beta$-C-linked azamannose- $(1 \rightarrow 6)$-glucose analogue 3 , for example, strongly inhibits amyloglucosidase $\left(\mathrm{IC}_{50}=12\right.$ $\mu \mathrm{M})$.[16] Aza-C-linked disaccharide mimetics are highly resistant to chemical and enzymatic hydolysis because a methylene group replaces the exo-oxygen of the glycosidic linkage, and the labile $O / N$ acetal functionality is avoided. The conformation of aza- $C$-linked glycosides appears to be largely governed by $1,3-$ syn diaxial interactions.[17]

In this paper, we report a general, two-directional approach to $\left(1 \rightarrow 1^{\prime}\right)$-aza- $C$-disaccharide mimetics. Unlike previous syntheses of aza- $C$-disaccharides,[16,18-23] neither of the heterocyclic rings is directly derived from a sugar, and, hence, analogues with unnatural or unusual configurations may be<smiles>CCOS(=O)(=O)NC(CC(O)c1ccco1)c1ccco1</smiles>

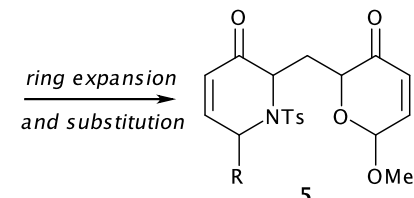

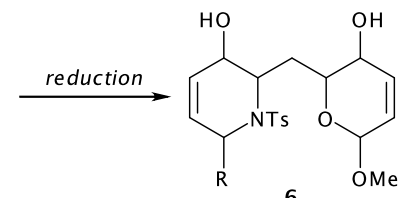

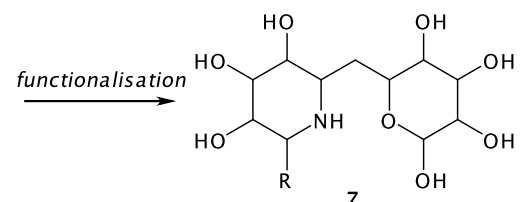

Scheme 1<smiles>O=[SH](=O)/N=C/c1ccco1</smiles>

8<smiles>C=C(O)c1ccco1</smiles>

$\mathrm{OLI}$<smiles>O=C(C[C@H](NS(=O)[O-])c1ccco1)c1ccco1</smiles>

$9,87 \%$
dias. $>95:<5$

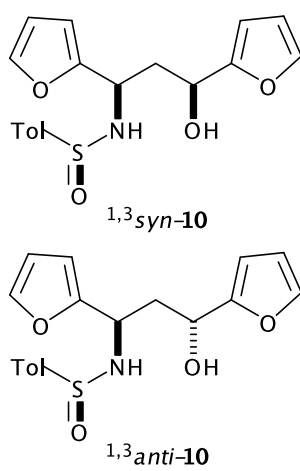

LiB HEt ${ }_{3}, \mathrm{THF},-78^{\circ} \mathrm{C}:{ }^{1,3}$ syn : ${ }^{1,3}$ anti $92: 8$ $\mathrm{LiAlH}_{4}$, THF, $-78^{\circ} \mathrm{C}$ : 1,3 syn : ${ }^{1,3}$ anti $29: 71$ 


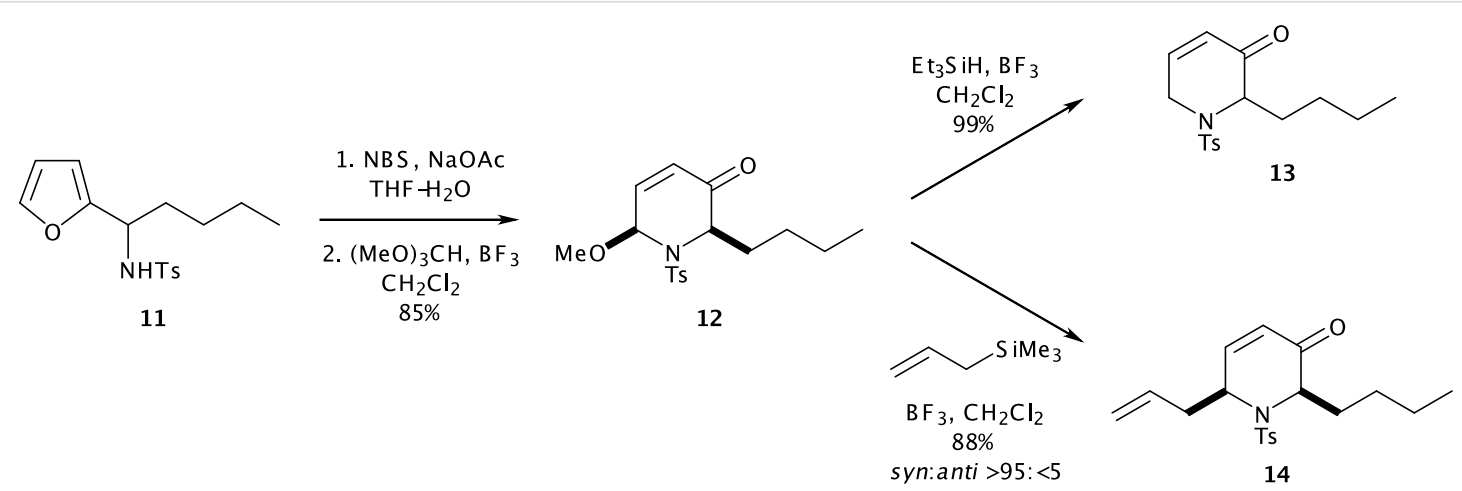<smiles>CCCC[C@H]1C(=O)C=C[C@@H](OC)N1S</smiles>

12

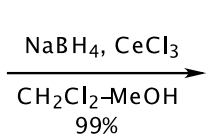

$99 \%$

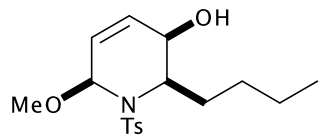

15, syn:anti $>95:<5$

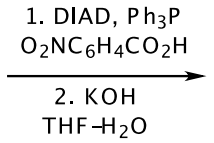

$85 \%$

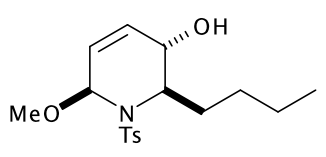

16<smiles>CCCCC1C(=O)C=CCN1C</smiles>

13<smiles>C=CC[C@@H]1C=CC(=O)[C@@H](CCCC)N1S</smiles>

14

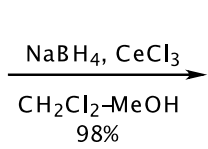

$98 \%$

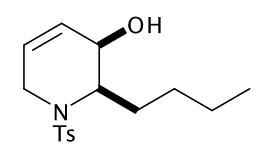

17, syn:anti $>95:<5$

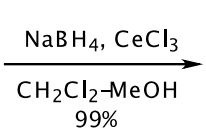

$99 \%$

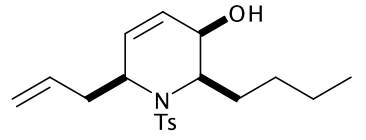

18, syn:anti $>95:<5$

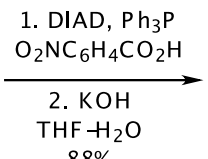

$88 \%$

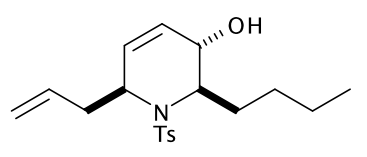

19

Scheme 4

easily prepared. Our synthetic strategy is outlined in Scheme 1. We have previously shown that the configuration of 1,3-amino alcohol derivatives, such as $\mathbf{1 0}$, may be controlled by the addition of a lithium enolate to an $N$-sulfinyl imine $(\rightarrow \mathbf{9}$, for example) and diastereoselective reduction (Scheme 2).[24-32] Two-directional[33] oxidative ring expansion of 1,3-difuryl 1,3amino alcohol derivatives 4 would yield a densely functionalised bis-enone which would be ripe for further functionalisation. The term "two-directional synthesis" is usually used to describe the elaboration of symmetrical substrates; [33] in this paper, we apply a two directional approach to the synthesis of highly unsymmetrical compounds. Indeed, a powerful feature of our approach is the potential to switch between two- and onedirectional synthetic steps; for example selective substitution of the piperidinyl $\mathrm{N}, \mathrm{O}$-acetal should be possible to yield the bisenones 5. Two-directional diastereoselective reduction $(\rightarrow \mathbf{6})$ and functionalisation would yield the protected aza- $C$-linked disaccharide analogues 7. Provided that the stereochemical outcome of the reduction and functionalisation steps may be controlled, as we have demonstrated for $C$-substituted monosaccharide[34] and $C$-linked disaccharide mimetics,[35-37] a wide range of stereochemically diverse aza- $C$-linked disaccharide analogues could be prepared (see piperidine ring systems A-D and tetrahydropyran ring systems $\mathrm{d}, \mathrm{d}^{\prime}$ and e). ${ }^{\dagger}$

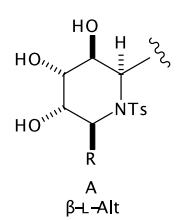

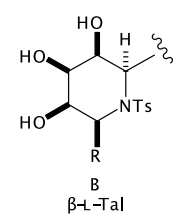

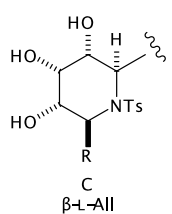<smiles>[2H]C1NC(C)(C)C(O)C(O)C1O</smiles><smiles>C[C@@H]1OC(O)[C@H](O)[C@@H](O)[C@H]1O</smiles><smiles>CC1OC(O)C(O)C(O)C1O</smiles><smiles>[2H]C1O[C@H](O)[C@H](O)[C@@H](O)[C@H]1O</smiles> 
${ }^{\dagger}$ In this paper, the final products are labelled according the configuration of the piperidine (A-D) and tetrahydropyran (d, d' or e) ring systems. Note that the ring systems $d$ and $d$ are enantiomeric.)

\section{Results and discussion Synthesis of substrates for model dihydroxylation reactions}

Methods for the diastereoselective functionalisation of piperidines were developed using a racemic model ring system. Oxidative ring expansion[38] of the 2-furyl sulfonamide 11, prepared by addition of $n$-butyl lithium to the $N$-tosyl imine of 2-furaldehyde,[39] was followed by protection to yield the piperidin-3-one 12 (Scheme 3). The $N, O$ acetal was substituted,[40] both by reduction $(\rightarrow \mathbf{1 3})$ and by allylation $(\rightarrow$ 14); the allylation reaction was highly diastereoselective $(>95:<5$ syn:anti), presumably as a result of a strong stereoelectronic preference for pseudo-axial attack on the intermediate iminium ion (with a pseudoaxial[40] butyl substituent) (Figure 1). The 2,6-cis relative configuration and pseudo-triaxial conformation of $\mathbf{1 4}$ have previously been established by X-ray crystallography.[40]

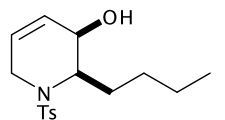

17

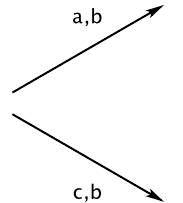<smiles>CCCC[C@H]1[C@H](O)C=C[C@@H](OC)N1C</smiles>

15

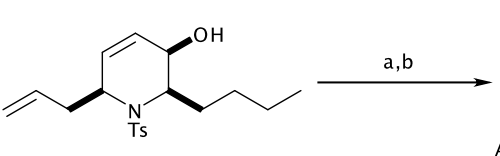

conditions a: $77 \%$, crude ratio: anti:syn $>95:<5$ conditions c: $4 \%$, crude ratio: anti:syn $>95:<5$

18

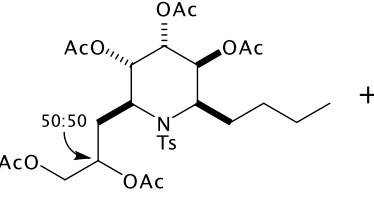

22A, $36 \%$ crude ratio: anti:syn $>95:<5$

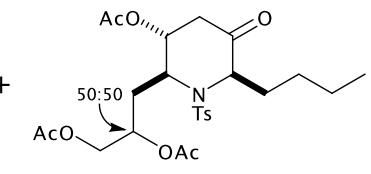

23, $27 \%$, dias. $>95:<5$

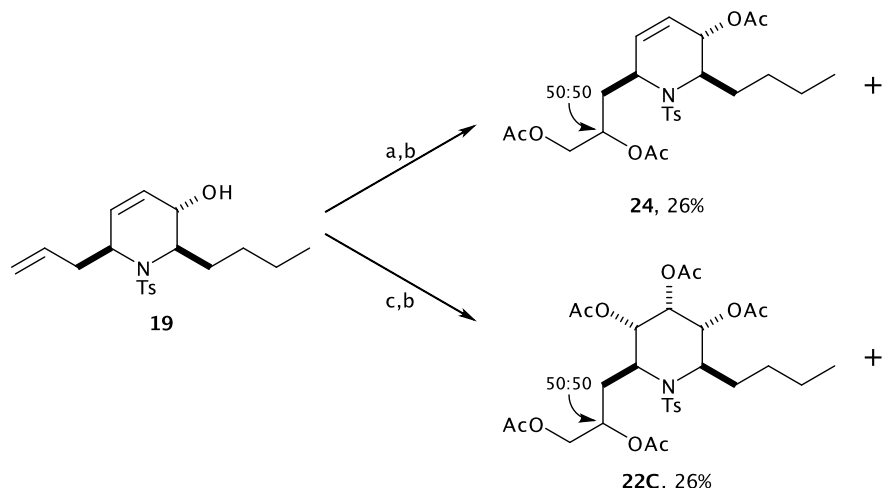<smiles>CC(=O)OCC(C)(C)OC(C)=O</smiles>
$23+22,42: 58,14 \% \quad 22 \mathrm{C}$<smiles>[CH]N(C[C@@H](COC(C)=O)OC(C)=O)[C@@H](C)CCCCC</smiles>

22D, $8 \%$

Conditions: (a) $\mathrm{NMO}$, cat. $\mathrm{OsO}_{4}$, acetone $-\mathrm{H}_{2} \mathrm{O}$; (b) $\mathrm{Ac}_{2} \mathrm{O}$, pyridine; (c) $\mathrm{OsO}_{4}, \mathrm{TMEDA}, \mathrm{CH}_{2} \mathrm{Cl}_{2},-78{ }^{\circ} \mathrm{C}$. 
The pyranones 12, 13 and $\mathbf{1 4}$ were reduced under Luche's[41, 42] conditions (Scheme 4). In each case, the reduction was highly $(>95:<5)$ diastereoselective in favour of the syn alcohol. The diastereoselectivity stems from pseudo-axial attack on the conformation in which unfavourable gauche interactions between the butyl and toluenesulfonyl groups (and where appropriate, the methoxy or allyl group) are minimised (Figure 2).[40] The allylic alcohols $\mathbf{1 5}$ and $\mathbf{1 8}$ were epimerised by Mitsunobu[43,44] inversion to yield the anti allylic alcohols 16 and 19.

\section{Diastereoselective dihydroxylation of a model system}

The diastereoselectivity of the dihydroxylation of the model compounds 15 and 17-19 was studied under both Upjohn[45] (cat. $\mathrm{OsO}_{4}, \mathrm{NMO}$, acetone-water) and Donohoe's[46] $\left(\mathrm{OsO}_{4}\right.$, TMEDA, $\mathrm{CH}_{2} \mathrm{Cl}_{2},-78^{\circ} \mathrm{C}$ ) reaction conditions (Scheme 5 and Table 1). In general, the crude reaction mixtures were peracetylated, analysed by $500 \mathrm{MHz}{ }^{1} \mathrm{H}$ NMR spectroscopy, and subsequently purified. The aim of the study was to investigate the scope and diastereoselectivity of the dihydroxylation reactions to the point that synthetically useful and complementary methods emerged; the most useful reactions were subsequently exploited in the two-directional synthesis of aza$C$-linked disaccharide derivatives.

For the syn allylic alcohols $\mathbf{1 5}, \mathbf{1 7}$ and $\mathbf{1 8}$, the dihydroxylation under Upjohn conditions was highly diastereoselective $(\rightarrow$

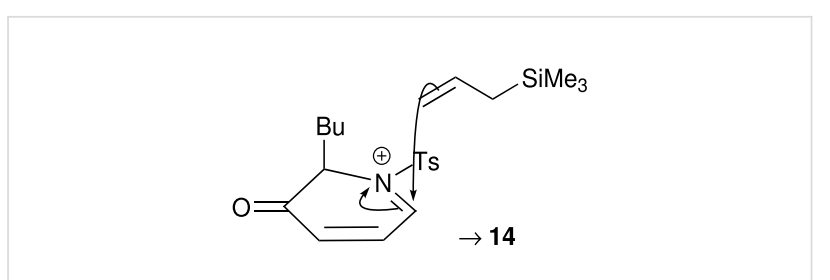

Figure 1: Diastereoselective substitution of the $\mathrm{N}, \mathrm{O}$ acetal 12

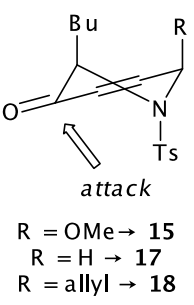

Figure 2: Diastereoselective Luche reduction of piperidinones

20A, 21A and 22A): dihydroxylation occurred anti to the hydroxyl group, and none of the syn product could be detected in the $500 \mathrm{MHz}{ }^{1} \mathrm{H}$ NMR spectra of the crude reaction mixtures (see Figure 3, and entries 1a, 3a and 5, Table 1). In the case of $\mathbf{1 8}$, the dihydroxylation of the allyl group was not diastereoselective, and a 50:50 mixture of epimers was obtained. The stereoelectronic preference for dihydroxylation anti to an allylic hydroxyl group has been recognised previously.[45] The

\begin{tabular}{|c|c|c|c|c|c|}
\hline entry & Starting material & Conditions $^{a}$ & anti:syn ${ }^{b}$ & Yield, anti (\%) & Yield, syn (\%) \\
\hline $1 a$ & 17 & $A, B$ & $>95:<5$ & 20A, 65 & - \\
\hline $1 b$ & 17 & $C, B$ & $<5:>95$ & - & 20B, 70 \\
\hline $2 a$ & 31 & $A, B$ & $>95:<5$ & 37Ad', 54 & - \\
\hline $2 b$ & 31 & $\mathrm{C}, \mathrm{B}$ & $<5:>95$ & - & 37Bb', 17 \\
\hline $3 a$ & 15 & $A, B$ & $>95:<5$ & 21A, 77 & - \\
\hline $3 b$ & 15 & $\mathrm{C}, \mathrm{B}$ & $>95:<5$ & 21A, 4 & - \\
\hline 4 & 29 & $A, B$ & $>95:<5$ & 38Ad', 16 & - \\
\hline 5 & 18 & $A, B$ & $>95:<5$ & $22 A, 36^{d, e}$ & - \\
\hline 6 & trans-27 & $A, B$ & $>95:<5$ & 39Ad', $61^{\mathrm{e}}$ & - \\
\hline 7 & trans-33 & $A, B$ & $>95:<5$ & $39 \mathrm{Ad}, 14^{\mathrm{e}}$ & - \\
\hline $8 a$ & 19 & $A, B$ & $<5:>95$ & - & $22 \mathrm{C},\left(8^{e, f}\right)$ \\
\hline $8 b$ & 19 & $C, B$ & ca. $25: 75$ & 22D, 89 & $22 \mathrm{C}, 26^{\mathrm{e}}$ \\
\hline 9 & cis-34 & $C, B$ & $h$ & 39De', $8^{h}$ & $39 \mathrm{Ce}^{\prime}, 23^{\mathrm{e}}$ \\
\hline
\end{tabular}

aConditions: $\mathrm{A}$ : $\mathrm{NMO}$, cat. $\mathrm{OsO}_{4}$, acetone-water; $\mathrm{B}: \mathrm{Ac}_{2} \mathrm{O}$, pyridine; $\mathrm{C}$ : $\mathrm{OsO}_{4}, \mathrm{TMEDA} \mathrm{CH}_{2} \mathrm{Cl}_{2},-78^{\circ} \mathrm{C}$. betermined by analysis of the crude product by $500 \mathrm{MHz}{ }^{1} \mathrm{H}$ NMR spectroscopy. The descriptors anti and syn refer to relative configuration of the pre-existing hydroxyl group and the new diol.

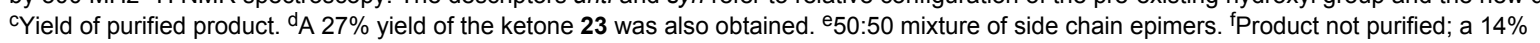
combined yield of a $42: 58$ mixture of $\mathbf{2 3}$ and $\mathbf{2 2 C}$ was isolated. In addition, $\mathbf{2 4}$ was obtained in $26 \%$ yield. ${ }^{9}>95:<5$ mixture of side chain epimers. ${ }^{\mathrm{h}}$ Not determined. i66:34 mixture of side chain epimers. 
yields of the reactions were rather variable. Good yields were obtained with the substrates $\mathbf{1 5}$ and $\mathbf{1 7}$, but, with the allylated substrate 18, the expected product, 22A, was accompanied by the separable epimeric by-products, 23: perhaps, anti-selective dihydroxylation of the internal alkene is followed by elimination of the resulting osmate ester. Alternatively, the by-product 23 may stem from oxidation to the corresponding $\alpha, \beta$-unsaturated ketone,[47] followed by conjugate addition.

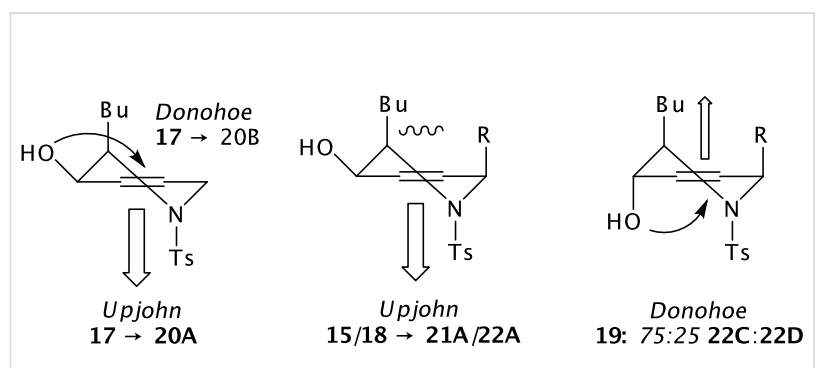

Figure 3: Diastereoselective dihydroxylation of unsaturated piperidines

The dihydroxyation of the anti allylic alcohol 19 under Upjohn conditions was not synthetically useful (entry 8a, Table 1). Although dihydroxyation of the remote allyl group was rapid, the dihydroxylation of the internal alkene was extremely sluggish, and a $26 \%$ yield of the mono-dihydroxylated product $\mathbf{2 4}$ was obtained. Both faces of the internal alkene are shielded by neighbouring pseudo-axial groups which must hinder the approach of the reagent. When dihydroxylation of the less reactive alkene did occur, the stereochemical outcome of the reactions was unusual,[45] yielding the syn product 22C in low yield. In addition, the reaction was plagued by the problems with elimination - to yield the $\beta$-hydroxy ketone $\mathbf{2 3}$ - that we had previously encountered (see the dihydroxylation of $\mathbf{1 8}$, above). Unfortunately, after peracetylation of the crude product, dihydroxylation of the remaining alkene of $\mathbf{2 4}$ under Donohoe's reaction conditions was not possible.

The dihydroxylation reactions performed using Donohoe's reaction conditions were, to some extent, complementary (for example, compare entry $1 \mathrm{a}$ with $1 \mathrm{~b}$, and entry $2 \mathrm{a}$ with $2 \mathrm{~b}$, Table 1). With the syn allylic alcohol 17, dihydroxylation was highly $(>95:<5)$ syn selective, yielding the triacetate 20B in $70 \%$ yield after peracetylation (entry $1 \mathrm{~b}$, Table 1 ). We have previously observed that the pseudo-equatorial allylic hydroxyl groups of similar dihydropyrans had been unable to direct the dihydroxylation process.[34-37] Here, however, dihydroxylation is highly syn selective, perhaps because the allylic position remote from the hydroxyl group is unsubstituted (see Figure 3). Indeed, the introduction of an allylic methoxy group in the 6-position of the piperidine ring, syn to the hydroxyl group,

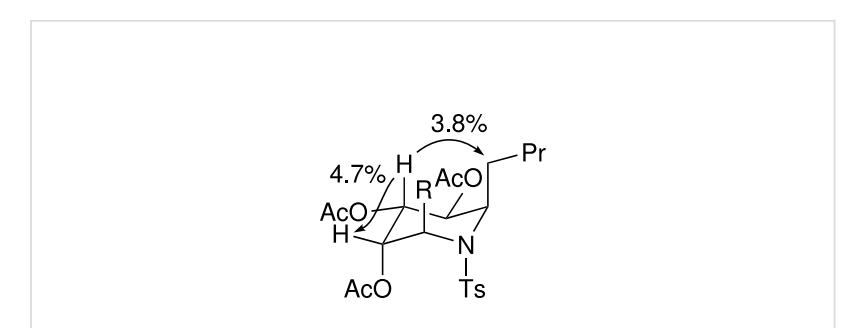

Figure 4: Diagnostic nOe observations for the piperidine 22A

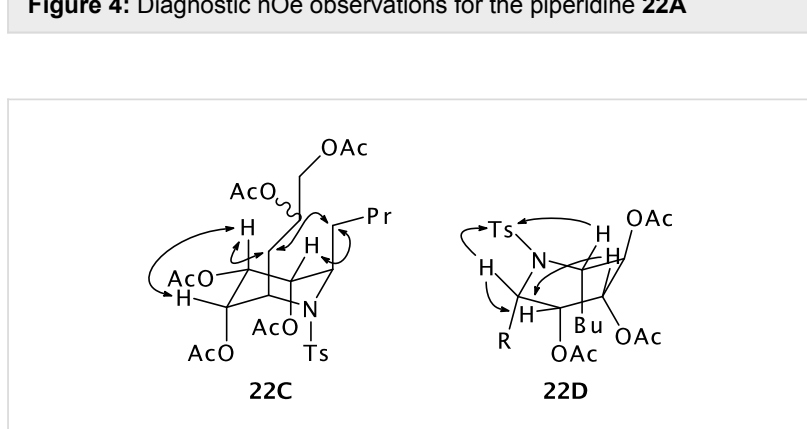

Figure 5: Diagnostic nOe observations for the piperidines 22C and 22D

prevented syn dihydroxylation: the face of the alkene $\mathbf{1 5}$ which is syn to both the hydroxy and methoxy groups - is extremely hindered, and an extremely low yield of the anti product $21 \mathrm{~A}$ was obtained (compare entry $1 \mathrm{~b}$ with entry $3 \mathrm{~b}$, Table 1).

The dihydroxylation of the anti allylic alcohol 19 was predominantly directed by the hydroxyl group, and the products $22 \mathrm{C}$ and 22D were obtained in $26 \%$ and $8 \%$ yield respectively after a rather sluggish acetylation reaction (entry $8 b$, Table 1). Here, with the butyl and $p$-toluenesulfonyl groups in pseudoaxial positions, [40] neither face of the alkene is hindered by two allylic substituents, and low diastereoselectivity was observed (see Figure 3). Remarkably, the pentaacetate 22D was obtained as a single side chain epimer.

\section{Determination of the configuration of the dihydroxylation products}

The relative configurations and conformations of the piperidines 20-22 were determined using a combination of three approaches: (a) analysis of the magnitude of vicinal coupling constants (see Table 2); (b) the observation of throughspace nOe correlations; and (c) molecular modelling using the MMFF force field. The determination of the relative configuration and conformation of the piperidines 20A, 20B, 21A and 22A was straightforward due the observation of large coupling constants between pairs of axial protons in the piperidine ring. Figure 4 summarises the diagnostic nOe connections for the piperidine 22A. 


\begin{tabular}{|c|c|c|c|c|c|c|c|c|}
\hline \multirow[b]{2}{*}{ Compound } & \multicolumn{4}{|c|}{ piperidine ring } & \multicolumn{4}{|c|}{ tetrahydropyran ring } \\
\hline & $J_{2,3}$ & $J_{3,4}$ & $J_{4,5}$ & $J_{5,6}$ & $J_{2,3}$ & $J_{3,4}$ & $J_{4,5}$ & $J_{5,6}$ \\
\hline 25d [13] & - & - & - & - & 9.8 & 9.8 & 3.5 & 1.7 \\
\hline $20 \mathrm{~A}$ & 4.6 & 10.9 & 3.2 & $a, a$ & - & - & - & - \\
\hline $21 \mathrm{~A}$ & 6.0 & 10.2 & 3.4 & $a$ & - & - & - & - \\
\hline 22A & 5.0 & 11.3 & 3.0 & 1.7 & - & - & - & - \\
\hline 37Ad' & $b$ & 10.4 & 3.1 & $1.5, a$ & 9.9 & 9.9 & 3.4 & 1.7 \\
\hline 38Ad' & 6.2 & 11.2 & 2.9 & 1.4 & 9.9 & 9.9 & 3.5 & 1.7 \\
\hline 39Ad' & 6.4 & 11.3 & 3.3 & 1.7 & 10.0 & 10.0 & 3.3 & 1.7 \\
\hline 39Ad & 6.4 & 11.3 & 2.6 & $a$ & 9.9 & 10.1 & 3.4 & 1.7 \\
\hline 20B & 6.4 & 3.0 & 3.0 & $11.6,5.3$ & - & - & - & - \\
\hline 37Bd' & 6.4 & 2.6 & 2.9 & $11.5,5.3$ & 9.9 & 10.1 & 3.4 & 1.7 \\
\hline $22 C$ & $b$ & $b$ & 3.3 & 3.3 & - & - & - & - \\
\hline $39 \mathrm{Ce}^{\prime}$ & $b$ & $b$ & $b$ & $b$ & 1.0 & 3.6 & 3.6 & 8.6 \\
\hline 22D & 0.6 & 4.9 & 3.1 & 6.6 & - & - & - & - \\
\hline 39De' & $a$ & 5.7 & 2.7 & 6.8 & a & 3.6 & 3.6 & 8.5 \\
\hline
\end{tabular}

${ }^{a}$ Broad peak. Small coupling constant not measured. ${ }^{b}$ Complex overlapped signals. Coupling constant not measured.

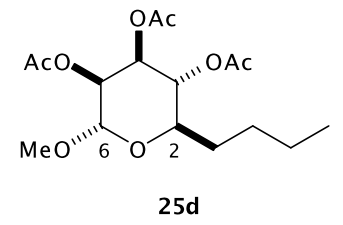

Minimisation of the structures of 22C and 22D allowed their ground state conformations to be predicted. The piperidine 22C was found to adopt a remarkably undistorted chair-like conformation with five axially-oriented substituents: presumably this conformation minimises 1,2-gauche interactions in spite of the 1,3-diaxial interactions that are necessarily incurred.[48,49] In contrast, 22D populates a distorted boat conformation, presumably in order to avoid unfavourable 1,3diaxial interactions between the $C-4$ acetoxy group and $C-2$ and C-6 methylene groups of the alternative chair conformer. Diagnostic nOe connections for the piperidines 22C and 22D are summarised in Figure 5.

\section{Two-directional synthesis of aza-C-linked disaccharide derivatives}

With the scope, limitations and complementarity of the dihydroxylations established, we turned to the two-directional synthesis of aza-C-linked disaccharide derivatives. The required starting materials were prepared from the 1,3-amino alcohol derivatives ${ }^{1,3}$ syn- and ${ }^{1,3}$ anti-10 (Scheme 6). Treatment of the difuryl 1,3-sulfinimido alcohols ${ }^{1,3}$ syn-and ${ }^{1,3}$ anti-
10 with NBS in buffered THF-water precipitiated sulfonamide oxidation and two-directional ring expansion of both furan rings; [50] the crude products were converted into the corresponding methyl $N, O$ and $O, O$ acetals 28 and 32. As has previously been observed,[34-38,48,49] the relative configuration of the $N, O$ acetals was completely controlled $\left({ }^{2,6} \mathrm{cis}:{ }^{2,6}\right.$ trans $>95:<5)$ and that of the $O, O$ acetals was poorly controlled $\left(2,6\right.$ cis: ${ }^{2,6}$ trans $\left.34: 66\right){ }^{*}$ The required substrates 28 and 32 were obtained in moderate (29-34\%) yield over two synthetic steps.

(* The descriptors trans and cis (see s Scheme 6 and Scheme 8) refer to the 2,6 stereochemical arrangement of the substituents (substituted methylene and methoxy) in the dihydropyran ring.)

For the syntheses of the allylated and reduced substrates, the crude products were treated directly with boron trifluoride etherate and either allyltrimethylsilane or triethylsilane. It was possible to switch cleanly to a one-directional synthesis because the $N, O$ acetals were much more susceptible to substitution under the reaction conditions. In each case, the required products (26 and 30) were obtained in moderate (30-37\% i.e. $67-71 \%$ per step) yield over the three synthetic steps as $66: 34$ mixtures of anomers. Nevertheless, the yields were deemed acceptable because, over the three steps, significant structural complexity had been introduced as a consequence of the twodirectional nature of the approach (sulfonamide oxidation, two oxidative ring expansions, two protection reactions and one 

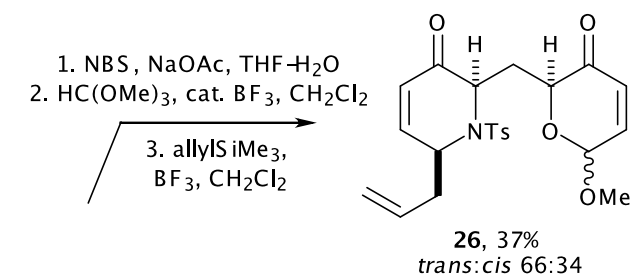<smiles>O=S(=O)(O)N[C@@H](CC(O)c1ccco1)c1ccco1</smiles>
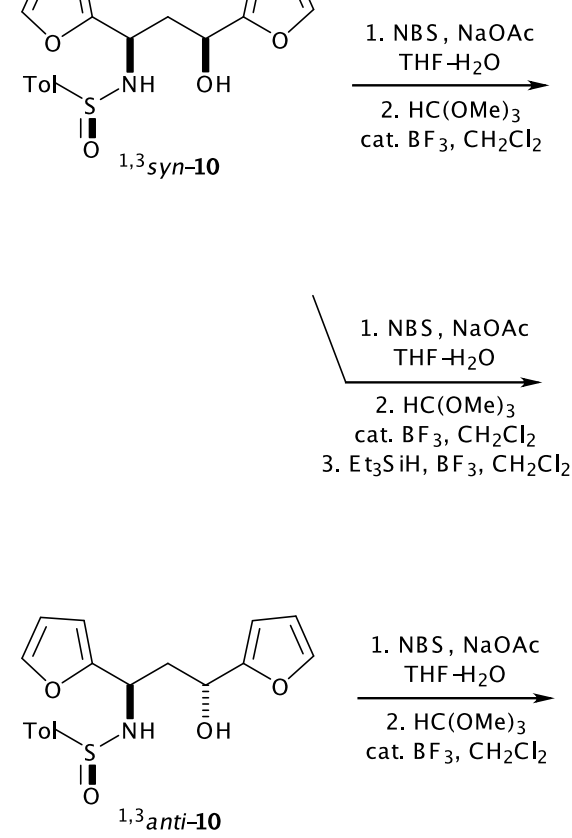

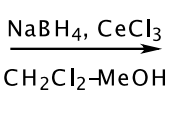<smiles>CO[C@H]1C=CC(=O)[C@@H](CC2C[NH2+]CC=CC2=O)O1</smiles>

$30,30 \%$ trans: cis $66: 34$ trans:
(trans $-30,14 \%)$<smiles>O=C1C=CC(=O)[C@@H](CC2O[C@H](O)C=CC2=O)O1</smiles>

$\underset{\mathrm{CH}_{2} \mathrm{Cl}_{2}-\mathrm{MeOH}}{\stackrel{\mathrm{NaBH}_{4}, \mathrm{CeCl}_{3}}{\longrightarrow}}$<smiles>C=CCC1C=CC(O)C(CC2O[C@H](O)C=C[C@@H]2O)N1</smiles>

trans-27, 52\%<smiles>C=CCC1C=C[C@H](O)[C@H](CC2OC(OC)C=C[C@@H]2O)N1</smiles>

cis $-27,19 \%$

$\stackrel{\mathrm{NaBH}_{4}, \mathrm{CeCl}_{3}}{\longrightarrow}$

$\mathrm{CH}_{2} \mathrm{Cl}_{2}-\mathrm{MeOH}$<smiles>CO[C@@H]1C=C[C@H](O)[C@H](C[C@@H]2O[C@@H](OC)C=C[C@H]2O)[NH2+]1</smiles>

29, 99\%, trans:cis 66:34 (trans-29, 35\%)<smiles>CO[C@@H]1C=C[C@@H](O)[C@H](C[C@H]2[C@@H](O)C=CCN2S)O1</smiles>

$31,>95: 5$

$83 \%$ from trans -30

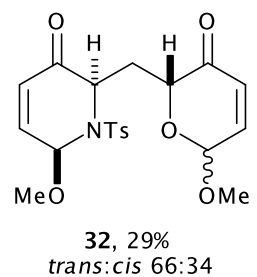

$\mathrm{NaBH}_{4}, \mathrm{CeCl}_{3}$ $\mathrm{CH}_{2} \mathrm{Cl}_{2}-\mathrm{MeOH}$<smiles>C[C@@H]1C=CC(O)C(O)(CC2[NH2+]C(O)C=CC2O)C1</smiles>

$33,92 \%$, trans:cis $66: 34$ (trans-33, 35\%)
$N, O$ acetal substitution reaction).

The stage was set for two-directional functionalisation of the heterocyclic rings. Although it had been possible to isolate trans-30 as a single anomer by careful column chromatography, the bis-enones 26, 28 and 32 were used directly in the reduction step as 66:34 anomeric mixtures. Twodirectional Luche[41,42] reduction of the bis-enones 26, 28, trans-30 and 32 was high yielding and highly $(>95:<5)$ diastereoselective. Fortunately, the anomers of the bis-allylic alcohols 27, 29 and 33 were separable by careful column chromatography. The stereochemical outcome of the Luche reduction had been remarkable: although the reaction had been highly diastereoselective in both heterocyclic rings, the sense of induction was different in each case. Presumably, the steric demands

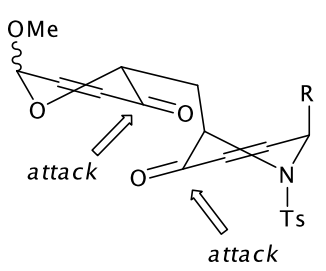

$\mathrm{R}=$ allyl: $26 \rightarrow 27$

$\mathrm{R}=$ OMe: $28 \rightarrow 29$

$\mathrm{R}=\mathrm{H}: 30 \rightarrow 31$

Figure 6: Stereoselectivity of two-directional Luche reductions

of the heteroatoms ( $N$-tosyl and $O$ ) control the reactive conformation of the heterocycles. The more sterically demanding $N$-tosyl group forces the piperidone rings to adopt 
1,2,6-tri-pseudo-axial conformations:[40] although the reducing agent still approaches the ketone from a pseudo-axial direction, the net stereochemical outcome is different (see Figure 6).

The configuration of both alcohols in the bis-allylic alcohols trans-27 and cis-27 was cleanly inverted using a Mitsunobu reaction, and the resulting diesters were hydrolysed to give the bis-allylic alcohols trans-34 and cis-34 respectively (Scheme 7). A key feature of our approach is the ability to switch as required between one- and two-directional synthetic modes as appropriate. We therefore investigated the possibility of selective inversion of one of the alcohols in the bis-allylic alcohol substrate trans-33: selective inversion of the piperidin3-ol was possible (91:9 selectivity between the alcohols).

Two-directional dihydroxylation, and peracetylation, yielded the aza- $C$-linked disaccharide derivatives (Scheme 8); the yields of products (Scheme 8, Table 1) refer to yields of pure products which were obtained, where necessary, by preparative HPLC. In all cases, the sterochemical outcome of the dihydroxylation reaction was similar to that observed in the model system (see Scheme 5). The relative configuration of the products was determined by comparison of their $500 \mathrm{MHz}{ }^{1} \mathrm{H}$ NMR spectra with those of the corresponding piperidine and tetrahydropyran model compounds (see Table 2).

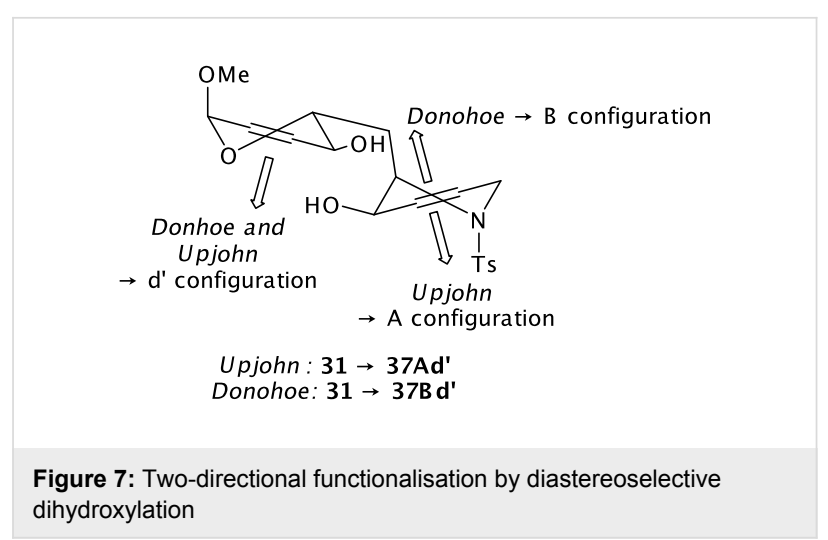

The outcome of the dihydroxylation of the bis-allylic alcohol 31 depended on the reagent used. Although dihydroxylation anti to the hydroxyl group in the dihydropyran ring was always observed ( $\rightarrow$ d' configuration),[34-37] reaction occurred either anti to (under Upjohn conditions) or syn to (under Donohoe's conditions) the hydroxyl group in the piperidine ring $(\rightarrow \mathrm{A}$ or B conuration respectively) (see Figure 7). In the synthesis of 37, the stereochemical outcome is different in each of the rings (syn to one hydroxyl group, and anti to the other).

With a substituent in the 6-position of the piperidine ring, the complementarity between the alternative methods was lost. With the substrates 29, trans-27 and trans-33, dihydroxylation<smiles>C=CC[C@H]1C=C[C@@H](O)[C@H](C[C@H]2O[C@H](OC)C=C[C@H]2O)[NH2+]1</smiles>

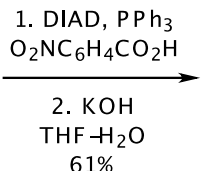<smiles>C=CCC1C=CC(O)[C@H](C[C@H]2OC(OC)C=C[C@H]2O)[NH2+]1</smiles>

cis -27

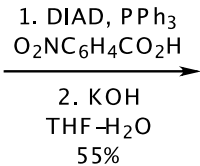<smiles>C=CCC1C=C[C@H](O)[C@H](C[C@H]2OC(OC)C=C[C@H]2O)[NH2+]1</smiles>

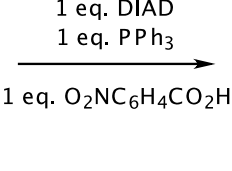<smiles>C=CC[C@H]1C=C[C@@H](O)[C@H](CC2O[C@H](OC)C=CC2O)[C@@H]1O</smiles><smiles>C=CCC1C=C[C@@H](O)[C@H](CC2OC(OC)C=C[C@H]2O)[C@@H]1O</smiles>

cis -34

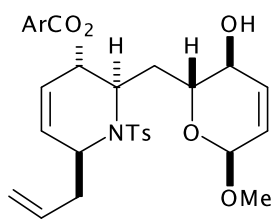

35

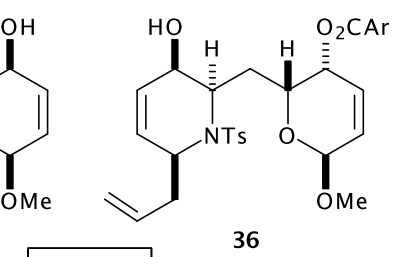



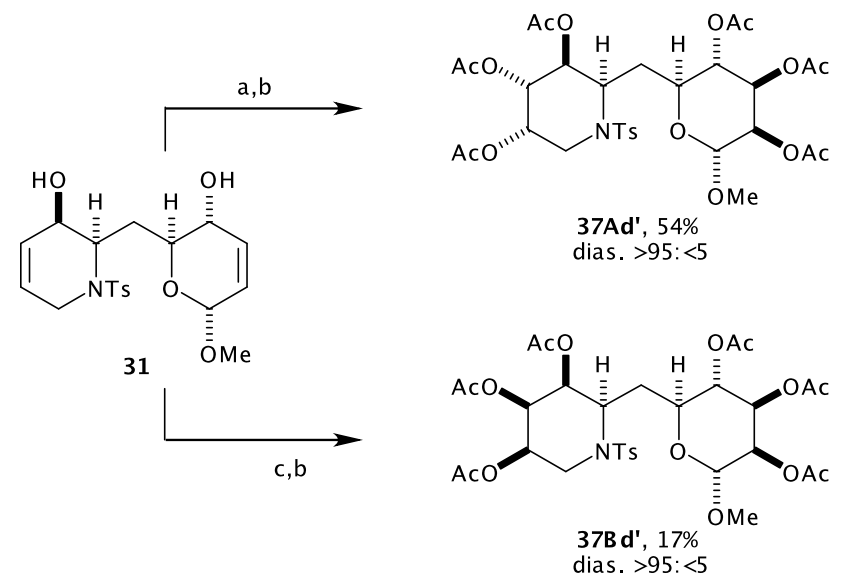<smiles>CO[C@H]1C=C[C@@H](O)C(C[C@@H]2O[C@@H](OC)C=C[C@H]2O)[NH2+]1</smiles>

29

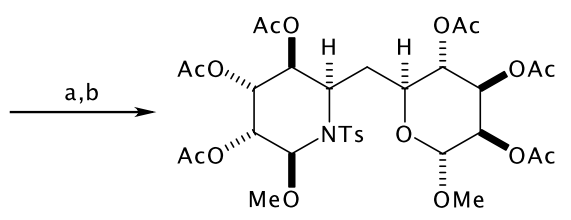

38Ad', $16 \%$ dias. $>95:<5$<smiles>C=CC[C@H]1C=CC(O)[C@H](CC2(C)C=C[C@H](O)O[C@@H]2O)[NH2+]1</smiles>

trans-27

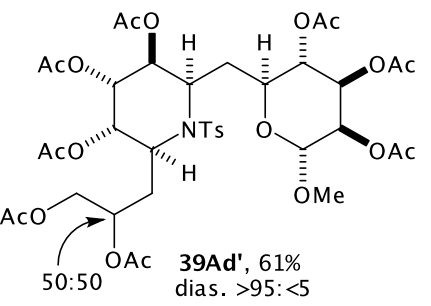<smiles>C=CC[C@H]1C=CC(O)[C@H](CC2(C)C=CC(O)O[C@@H]2O)[NH2+]1</smiles>

trans -33
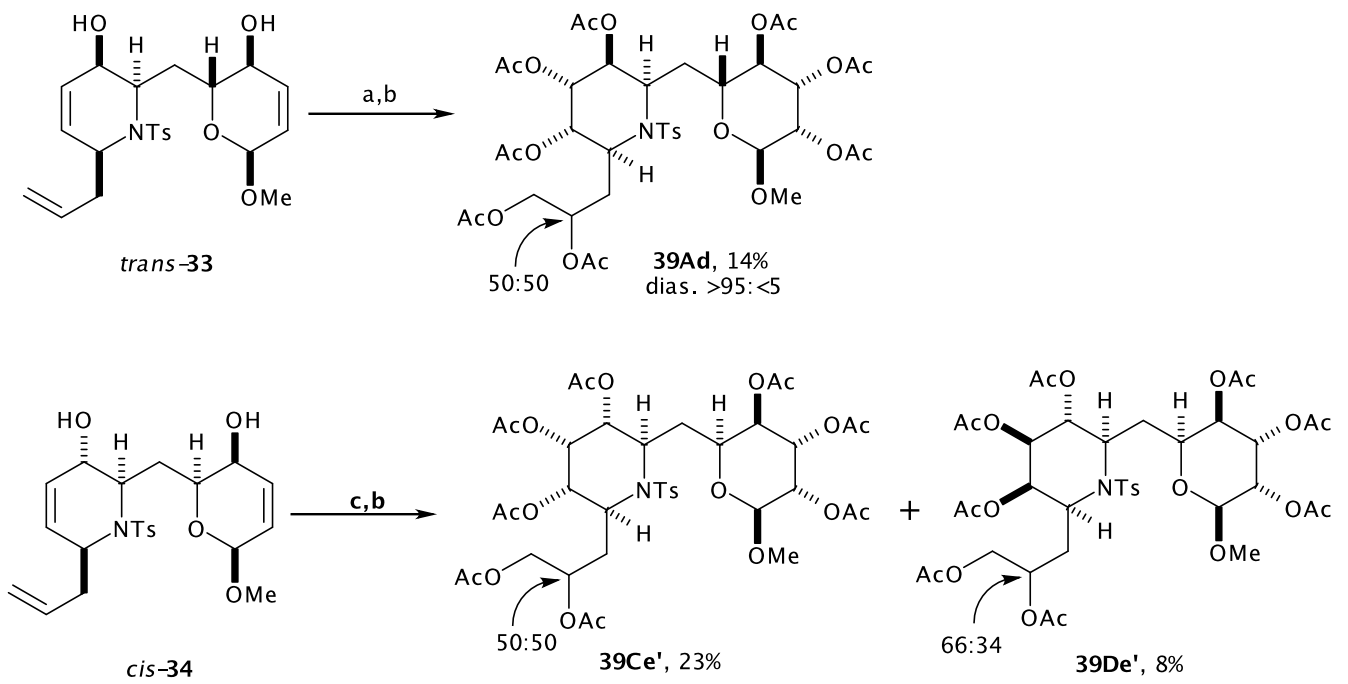

Conditions: (a) $\mathrm{NMO}$, cat. $\mathrm{OsO}_{4}$, acetone $-\mathrm{H}_{2} \mathrm{O}$; (b) $\mathrm{Ac}_{2} \mathrm{O}$, pyridine; (c) $\mathrm{OsO}_{4}, \mathrm{TMEDA}, \mathrm{CH}_{2} \mathrm{Cl}_{2},-78{ }^{\circ} \mathrm{C}$. 
occurred anti to the hydroxyl group in each of the rings, yielding the products 38Ad', 39Ad' and 39Ad respectively. Although not observed, it is probable that competing oxidation to a ketone analogous to $\mathbf{2 3}$ may have occurred in some cases. The yield of 39Ad' is surprisingly high compared to the corresponding model compound, $22 \mathrm{~A}$, where the by-product $\mathbf{2 3}$ had been isolated in $27 \%$ yield (compare entries 5 and 6 , Table 1). The yield of 38Ad' was surprisingly low compared to the corresponding model compound (21A), perhaps a consequence of the difficulty of the HPLC purification in this case.

With the doubly inverted bis-allylic alcohol cis-34, the diastereoisomeric aza- $C$-linked disaccharide derivatives 39Ce' and 39De' were obtained in $23 \%$ and $8 \%$. The diastereoselectivity, and the yields of the products, compare well with that observed in the relevant model system, 19 (compare entries $8 \mathrm{~b}$ and 9 , Table 1).

\section{Conclusion}

An asymmetric two-directional approach to the synthesis of some aza-C-linked disaccharide derivatives has been developed. The approach is reasonably general, allowing considerable control over the relative configuration of the products. Unlike the previous syntheses of aza- $C$-linked disaccharides, neither of the heterocyclic rings was directly derived from a sugar; therefore a wide range of compounds which mimic unusual disaccharides was prepared. In each synthesis, ten or eleven new stereogenic centres were controlled, either directly or indirectly, from a single stereogenic centre in Ellman's $p$-toluenesulfinyl chiral auxiliary. The source of the asymmetry means that the approach would be amenable to the synthesis of the enantiomeric aza- $C$-linked disaccharide derivatives. A key feature of the approach was the potential to switch between one- and two-directional synthetic steps, allowing the selective introduction of a range of 6-piperidinyl substituents. Furthermore, the stereochemical outcome of the functionalisations of the piperidine and tetrahydropyran rings was often different, adding to the diversity of the products prepared.

\section{Description of additional material}

Experimental procedures are provided for the synthesis of all compounds described.

\section{Supporting Information}

\section{Supporting Information File 1}

Experimental details

[http://www.beilstein-journals.org/bjoc/content/

supplementary/1860-5397-1-2-S1.doc]

\section{Acknowledgments}

We thank EPSRC and GlaxoSmithKline for funding, and the EPSRC National Mass Spectrometry Service, Swansea, for analyses.

\section{References}

1. Fleet, G. W. J.; Karpus, A.; Dwek, R. A.; Fellows, L. E.; Tyms, A. S.; Petursson, S.; Namgoong, S. K.; Ramsden, N. G.; Smith, P. W.; Son J. C.; Wilson, F. X.; Witty, D. R.; Jacob, G. S.; Rademacher, T. W. FEBS Lett. 1988, 237, 128-132. doi:10.1016/0014-5793(88)80185-6

2. Winchester, B.; Fleet, G. W. J. Glycobiology 1992, 2, 199-210.

3. Elbein, A. D. Annu. Rev. Biochem. 1987, 56, 497-534. doi:10.1146/ annurev.bi.56.070187.002433

4. Hettkamp, H.; Legler, G.; Bause, E. Eur. J. Biochem. 1984, 142, 85-90. doi:10.1111/j.1432-1033.1984.tb08253.x

5. Elbein, A. D.; Legler, G.; Tlutsy, A.; McDowell, W.; Schwarz, R. Arch. Biochem. Biophys. 1984, 235, 579-588. doi:10.1016/0003-9861(84) 90232-7

6. Sinnot, M. L. Chem. Rev. 1990, 90, 1171-1202. doi:10.1021/ cr00105a006

7. Gruters, R. A.; Neefjes, J. J.; Tersmette, M.; de Goede, R. E.; Tulp, A.; Huisman, H. G.; Miedema, F.; Plough, H. L. Nature 1987, 330, 74-76. doi:10.1038/330074a0

8. Walker, B. D.; Kowalski, M.; Goh, W. C.; Kozarsky, K.; Krieger, M.; Rosen, C.; Rohrschneider, L.; Haseltine, W. A.; Sodroski, J. Proc. Natl. Acad. Sci. U. S. A. 1987, 84, 8120-8124.

9. Karpus, A.; Fleet, G. W. J.; Dwek, R. A.; Petursson, S.; Namgoong, S. K.; Ramsden, N. G.; Jacob, G. S.; Rademacher, T. W. Proc. Natl. Acad. Sci. U. S. A. 1988, 85, 9229-9233.

10. von Itzstein, M.; Wu, W.-Y.; Kok, G. B.; Pegg, M. S.; Dyason, J. C.; Jin, B.; Phan, T. V.; Smythe, M. L.; Whitem, H. F.; Oliver, S. W.; Colman, P. M.; Varghese, J. N.; Ryan, D. M.; Woods, J. M.; Bethell, R. C.; Hotham, V. J.; Cameron, J. M.; Penn, C. R. Nature 1993, 364, 418-423. doi:10.1038/363418a0

11. Humphries, M. J.; Matsumoto, K.; White, S. L.; Olden, K. Cancer Res. 1986, 46, 5215-5222.

12. Spearman, M. A.; Jamieson, J. C.; Wright, J. A. Exp. Cell Res. 1987, 168, 116-126. doi:10.1016/0014-4827(87)90421-6

13. Truscheit, E.; Frommer, W.; Junge, B.; Müller, L.; Schmidt, D. D.; Wingender, W. Angew. Chem., Int. Ed. Engl. 1981, 20, 744-761. doi:10.1002/anie.198107441

14. Horii, S.; Fukase, H.; Matsuo, T.; Kameda, Y.; Asano, N.; Matsui, K. J. Med. Chem. 1986, 29, 1038-1046. doi:10.1021/jm00156a023

15. Anzeveno, P. B.; Creemer, L. J.; Daniel, J. K.; King, C.-H. R.; Lui, P. S. J. Org. Chem. 1989, 54, 2539-2542. doi:10.1021/jo00272a015

16. Johns, B. A.; Pan, Y. T.; Elbein, A. D.; Johnson, C. R. J. Am. Chem. Soc. 1997, 119, 4856-4865. doi:10.1021/ja9642929

17. Asensio, J. L.; Cañada, F. J.; García-Herrero, A.; Murillo, M. T.; Fernández-Mayoralas, A.; Johns, B. A.; Kozak, J.; Zhu, Z.; Johnson, C. R.; Jiménez-Barbero, J. J. Am. Chem. Soc. 1999, 121, 11318-11329. doi:10.1021/ja9922734

18. Johnson, C. R.; Miller, M. W.; Golebiowski, A.; Sundram, H.; Ksebati, M. B. Tetrahedron Lett. 1994, 35, 8991-8994. doi:10.1016/00404039(94)88408-0

19. Baudat, A.; Vogel, P. Tetrahedron Lett. 1996, 37, 483-484. doi:10.1016/0040-4039(95)02214-7

20. Martin, O. R.; Liu, L.; Yang, F. Tetrahedron Lett. 1996, 37, 1991-1994. doi:10.1016/0040-4039(96)00226-2 
21. Frérot, E.; Marquis, C.; Vogel, P. Tetrahedron Lett. 1996, 37, 2023-2026. doi:10.1016/0040-4039(96)00189-X

22. Saavedra, O. M.; Martin, O. R. J. Org. Chem. 1996, 61, 6987-6993. doi:10.1021/jo960362i

23. Cheng, X.; Kumaran, G.; Mootoo, D. R. Chem. Commun. 2001, 811-812. doi:10.1039/b101598m

24. Kennedy, A.; Nelson, A.; Perry, A. Synlett 2004, 967-971.

25. Davis, F. A.; Yang, B. Org. Lett. 2003, 5, 5011-5014. doi:10.1021/ ol035981+

26. Tang, T. P.; Ellman, J. A. J. Org. Chem. 2002, 67, 7819-7832. doi:10.1021/jo025957u

27. Koriyama, Y.; Nozawa, A.; Hayakawa, R.; Shimizu, M. Tetrahedron 2002, 58, 9621-9628. doi:10.1016/S0040-4020(02)01250-4

28. Huang, L.; Brinen, L. S.; Ellman, J. A. Bioorg. Med. Chem. 2003, 11, 21-29. doi:10.1016/S0968-0896(02)00427-3

29. Davis, F. A.; Prasad, K. R.; Nolt, M. B.; Wu, Y. Org. Lett. 2003, 5, 925-928. doi:10.1021/ol034119z

30. Jacobsen, M. F.; Skrydstrup, T. J. Org. Chem. 2003, 68, 7112-7114. doi:10.1021/jo034436j

31. Davis, F. A.; Chao, B. Org. Lett. 2000, 2, 2623-2625. doi:10.1021/ ol0061438

32. Davis, F. A.; Yang, B.; Deng, J. J. Org. Chem. 2003, 68, 5147-5152. doi:10.1021/j0030081s

33. Poss, C.; Schreiber, S. L. Acc. Chem. Res. 1994, 27, 9-17. doi:10.1021/ar00037a002

34. Hodgson, R.; Majid, T.; Nelson, A. J. Chem. Soc., Perkin Trans. 1 2002, 1444-1454. doi:10.1039/b202890e

35. Harding, M.; Nelson, A. Chem. Commun. 2001, 695-696. doi:10.1039/ b101196k

36. Hodgson, R.; Majid, T.; Nelson, A. Chem. Commun. 2001, 2076-2077. doi:10.1039/b107643d

37. Harding, M.; Hodgson, R.; Majid, T.; McDowall, K. J.; Nelson, A. Org. Biomol. Chem. 2003, 1, 338-349. doi:10.1039/b208781b

38. Ciufolini, M. A.; Wood, C. Y. Tetrahedron Lett. 1986, 27, 5085-5088. doi:10.1016/S0040-4039(00)85139-4

39. Zhou, W.-S.; Lu, Z.-H.; Wang, Z.-M. Tetrahedron 1993, 49, 2641-2654. doi:10.1016/S0040-4020(01)86343-2

40. Hopman, J. C. P.; van den Berg, E.; Ollero, L. O.; Hiemstra, H.; Speckamp, W. N. Tetrahedron Lett. 1995, 36, 4315-4318. doi:10.1016/ 0040-4039(95)00748-2

41. Luche, J.-L. J. Am. Chem. Soc. 1978, 100, 2226-2227. doi:10.1021/ ja00475a040

42. Cassidy, M. P.; Padwa, A. Org. Lett. 2004, 6, 4029-4031. doi:10.1021/ ol048326q

43. Hughes, D. L. The Mitsunobu Reaction. In Organic Reactions; Paquette, L. A., Ed.; Wiley: New York, 1992; Vol. 42, pp 335-656.

44. Haukaas, M. H.; O'Doherty, G. A. Org. Lett. 2001, 3, 401-404. doi:10.1021/ol006907j

45. Cha, J. K.; Christ, W. J.; Kishi, Y. Tetrahedron 1984, 40, 2247-2255. doi:10.1016/0040-4020(84)80008-3

46. Donohoe, T. J.; Blades, K.; Moore, P. R.; Waring, M. J.; Winter, J. J. G.; Helliwell, M.; Newcombe, N. J.; Stemp, G. J. Org. Chem. 2002, 67, 7946-7956. doi:10.1021/jo026161y

47. Majetich, G.; Defauw, J.; Ringold, C. J. Org. Chem. 1988, 53, 50-68. doi:10.1021/jo00236a013

48. Corey, E. J.; Sarakinos, G.; Fischer, A. Tetrahedron Lett. 1999, 40, 7745-7748. doi:10.1016/S0040-4039(99)01641-X

49. Riera, A.; Pericà, M. A.; Cabré, F. Tetrahedron Lett. 1990, 31 , 2755-2758. doi:10.1016/S0040-4039(00)94691-4
50. Achmatowicz, O., Jr.; Bukowski, P.; Szechner, B.; Zwierzchowska, Z.; Zamojski, A. Tetrahedron 1971, 27, 1973-1996. doi:10.1016/S00404020(01)98229-8

\section{License and Terms}

This is an Open Access article under the terms of the Creative Commons Attribution License

(http://creativecommons.org/licenses/by/2.0), which permits unrestricted use, distribution, and reproduction in any medium, provided the original work is properly cited.

The license is subject to the Beilstein Journal of Organic Chemistry terms and conditions:

(http://www.beilstein-journals.org/bjoc)

The definitive version of this article is the electronic one which can be found at:

doi:10.1186/1860-5397-1-2 